\title{
Doença e cura na etnomedicina Guarani Nhandeva: o médico e o xamã
}

Disease and cure in the etnomedicine Guarani Nhandeva: the doctor and the shaman

\author{
Erneldo Schallenberger* \\ Jovane Gonçalves dos Santos ${ }^{\star \star}$
}

Palavras-chave:

Saúde-doença

Etnomedicina Guarani

Tekohá Añetete

Keywords:

Health-disease

Ethnomedicine Guarani

Tekohá Añetete
Resumo: Este artigo discute a concepção de saúde-doença para os Guarani, do subgrupo Nhandeva, da aldeia Tekohá Añetete. Adotando método da observação participante, buscou-se responder a questões como: O que é saúde e o que é doença para os Guarani? Para que servem os remédios industrializados? Estas questões assumem centralidade frente à necessidade de se considerar o pensamento nativo na formulação da Política Nacional de Atenção à Saúde Indígena. O estudo revelou que o adoecimento de um sujeito está ligado ao afastamento de sua alma; a cura é feita pelo rezador (karaí), não pelos remédios, que, no máximo, podem aliviar os sintomas. A alma de um enfermo só se reaproxima dele através do karaí, que promove a cura e restabelece a saúde.

\begin{abstract}
This article discusses the concept of health and illness for the Guarani, the Nhandeva subgroup, the village Tekohá Añetete. Adopting method of participant observation, we tried to answer questions such as: What is health and what is illness for the Guarani? What are the industrialized remedies? These issues are central front of the need to consider the native thought in the National Policy of Attention to Indigenous Health. The study revealed that the condition of a subject is linked to the remoteness of his soul; the curing is performed by the religious leader prayer (Karaí), not by drugs, these can at most alleviate the symptoms. The soul of a sick person only reconnecting it through Karai work; This rather promotes healing and restores health. The soul of a sick person only reconnecting it through Karai work; This rather promotes healing and restores health.
\end{abstract}

Recebido em 22 de dezembro de 2017. Aprovado em 27 de dezembro de 2017.

\section{Introdução}

Nos últimos anos, o debate acerca da saúde indígena vem ganhando relativa visibilidade na esfera das políticas públicas. Nas discussões, são ouvidos diversos técnicos e especialistas ligados à medicina dos "brancos". É pertinente e necessário dar atenção, também, às teorias nativas. Nesse sentido, o presente artigo propõe-se discutir o que é saúde e doença na perspectiva dos indígenas Guarani, pertencentes ao subgrupo Nhandeva, moradores da Comunidade Tekohá Añetete, no Município Diamante do Oeste, no Estado do Paraná.
Ao longo dos anos, a Política Nacional de Atenção à Saúde Indígena implantou, dentro das aldeias, os postos de saúde com equipe básica composta por médico, enfermeiro, técnico em enfermagem, agente de saúde e odontólogo. Tais postos estão referenciados a um "Polo Base" e são apoiados pelas Casas de Saúde do Índio.

Essa organização facilitou o acesso dos indígenas aos serviços médicos, bem como aos medicamentos industrializados, fato que é bastante elogiado pelos Guarani do Oeste do Paraná. Contudo, a organização dessa estrutura centrou os holofotes do debate na logística da política de saúde

\footnotetext{
* Doutor (2001) em História pela Pontifícia Universidade Católica do Rio Grande do Sul, com Pós-Doutorado em História, Cultura e Poder pela Universidade Federal do Paraná (2008-2009). Professor sênior na Universidade Estadual do Oeste do Paraná. E-mail: <erneldo@uol.com.br>.

** Antropólogo; Mestre em Ciências Sociais pelo Programa de Pós-Graduação em Ciências Sociais da Universidade Estadual do Oeste do Paraná.
} 
e deixou na sombra o pensamento nativo. O que é saúde para os indígenas? O que é doença? Para que servem os remédios nas sociedades tradicionais? Os remédios podem estragar o corpo dos indígenas? São questões que ainda não foram suficientemente respondidas e que o presente estudo responderá a partir de pesquisa desenvolvida junto a uma comunidade Guarani Nhandeva.

Eliana Elisabeth Dihel (2001) destaca que na formulação da política de saúde o entendimento dos povos indígenas não foi suficientemente considerado. Existem estudos clássicos como os desenvolvidos por León Cadogan (1948), Moisés Santiago Bertoni (1927 e Pedro Montenegro (2007), que já se debruçaram sobre o tema da saúde e das doenças entre os Guarani, destacando a higiene, os conhecimentos científicos e as práticas medicinais cultivadas entre eles. Não houve, entretanto, um aprofundamento acerca dos diversos fatores que influenciam o acesso e o consumo dos medicamentos e, tampouco, uma reflexão por parte dos planejadores e executores das políticas de saúde sobre as práticas e a simbologia que envolve a etnomedicina Guarani. O presente estudo vem dar visibilidade a esse saber, até agora marginalizado, e pretende contribuir para as futuras análises e avaliações das políticas de saúde no contexto das sociedades indígena.

O trabalho é produto de pesquisa etnográfica realizada na aldeia Guarani Tekohá Añetete, localizada no município de Diamante do Oeste, no Estado do Paraná. Convivendo pelo período de seis meses nessa comunidade e participando do dia-adia dos indígenas, procuramos entender o modo de pensar dessa sociedade para captarmos e "levarmos a sério", segundo expressão de Viveiros de Castro (2000), as teorias nativas.

\section{Quem são os Guarani?}

Os indígenas Guarani compõem etnias pertencentes à família linguística tupi-guarani, do tronco Tupi; geograficamente falando, concentramse nos territórios hoje identificados como pertencentes aos estados nacionais da Argentina, do Brasil, da Bolívia, do Paraguai e do Uruguai do Uruguai. Eles, os Guarani, não reconhecem os limites territoriais impostos por esses estados. Percebem tais espaços a partir de uma lógica própria; daí ser tão comum observar seus deslocamentos para além das fronteiras embandeiradas pelos países em questão.

No Brasil, os Guarani se dividem, segundo Egon Schaden (1962), nas parcialidades Mbyá, Nhandeva e Kaiowá; sendo que os Mbyá se subdividem ainda em Chiripá, Tambeopé e Paim (MELLO, 2007).

No oeste do Paraná a grande maioria dos indígenas são Nhandeva, alguns poucos Mbyá Chiripá e outros, em menor quantidade, Mbyá Paim. No entanto, no discurso "pra fora", construído para os "brancos", eles dizem que integram apenas comunidades Nhandeva. É assim que os identificamos ao longo deste trabalho, por sabermos que é assim que esses sujeitos querem ser identificados e por percebermos que a maioria numérica deles é, de fato, Nhandeva, mesmo que nas relações cotidianas fique claro que não se trata de um grupo capaz de expressar a identificação de todos os indivíduos.

A diferença entre esses subgrupos é estabelecida especialmente através da linguagem e dos hábitos que julgam corretos (nhanderekó). De um grupo para o outro variam os sentidos das palavras, a pronúncia e, principalmente, as normas que orientam a vida.

Como a maioria dos demais povos indígenas contemporâneos, esses Guarani não correspondem ao estereótipo de "índio" (despido, selvagem e com penas no corpo) presente no imaginário de boa parte da população brasileira. Os sujeitos com quem essa pesquisa se constrói são indígenas que estão em muitos lugares; estão nas escolas urbanas, nos transportes coletivos, nas praças, nas rodoviárias, nos estabelecimentos comerciais; consomem produtos industrializados, têm acesso a tecnologias, convivem diariamente com "brancos" sem, no entanto, deixarem o modo "indígena" ser e de conceber o mundo. A forma como pensam e teorizam as questões de saúde-doença é uma evidência disso.

Embora convivendo com a sociedade envolvente e consumindo os remédios produzidos pela farmacologia ocidental, os Guarani teorizam 
sobre saúde e doença de um jeito muito particular. Essa teoria "nativa" em nada lembra a concepção médica convencional. $\mathrm{Na}$ etnomedicina guarani a doença tende a ser vista como uma categoria cultural e como um conjunto de eventos culturais relacionados, como já tem assinalado Horácio Fabrega (1971). É possivel perceber, no convívio com estes sujeitos, uma simbolização que permite estabelecer uma relação entre doença, comportamento individual e social e adaptação ao meio. Para explicar as patologias, a alma é um elemento essencial nessa cultura, conforme veremos a seguir.

\section{A alma na percepção da saúde e da doença}

Para os Guarani Nhandeva, os homens possuem uma alma que é denominada pelo conceito nhẻe. Ela é responsável pela condução do indivíduo a viver de maneira correta a vida (nhanderekó); tal maneira também é condição para que a alma permaneça junto do sujeito. O afastamento da nhe'e leva a pessoa ao adoecimento ou, até mesmo, à morte.

Quando o feto está sendo gestado, a nhe'e da criança começa a ser preparada por Nhanderu, o Deus, para vir acompanhá-la na terra. À medida que se aproxima o nascimento, a alma começa a "caminhar" do seu local de origem em direção ao sujeito que deverá nascer. Ela provém de muitos lugares: da morada de Tupã, da Terra sem Mal, do Sol, do som de um instrumento, entre outros; todos eles se localizam no cosmos e, em cada um, existe um amba (espécie de altar) de onde o Deus ordena que a alma saia para vir à Terra. A alma dos filhos, conforme já registrou Silva (2007), tende a vir do mesmo local de onde emanou a alma de seus pais, embora isso não possa ser tomado como regra.

O lugar de onde se origina a alma determina o nome que será dado ao novo Guarani. Um dos informantes explicou que sua nhe'e veio da Terra Sem Mal, um paraíso onde as coisas tendem a ser de cor amarelada; por isso ele foi nomeado Avá Negaju, traduzido como "homem de brilho amarelo". Outra informante, chamada Takua Mirin, disse que sua nhẻe veio do som do takuá, instrumento musical executado pelas mulheres na Casa de Rezas $(O p y)$. O local, a partir de onde caminha a alma de um sujeito, é identificado pelo pajé, ou xamã, que, portanto, é capaz de dizer qual deve ser o nome da criança que está diante de si. Refletindo sobre esse poder do xamã, Curt U. Nimuendaju nos apresenta a seguinte passagem:

Eles (os Guarani) acham profundamente ridículo que o sacerdote cristão, que sempre se julga superior ao pajé pagão, pergunte aos pais da criança como esta deveria se chamar. Pretende que é padre e sequer é capaz de determinar o nome certo da criança. (NIMUENDAJU, 1987, p. 32)

Desde a gestação até o momento em que a criança é nomeada, a alma estava se dirigindo à pessoa; é por isso que nessa fase o Guarani necessita de atenção especial, pois ele ainda não tem a sua alma devidamente perto de si. É também por isso que as doenças costumam atingir mais as crianças; uma pessoa sem a sua nhe'e adoece. Doença é uma questão de alma distante.

A maneira para se evitar as doenças infantis é cuidar da criança para que sua alma não desista dela. Qualquer descuido pode levar a nhe'e a retornar para seu lugar de origem, ocasionando o adoecimento e a morte do indivíduo. Todo o esforço dos pais, dos familiares e dos padrinhos precisa ser no sentido de demonstrar à alma que, uma vez na terra, será bemquista e terá parentes sempre próximos dela para alegrá-la e ensiná-la a viver do modo que entendem ser correto (nhanderekó).

O nhanederekó corresponde a um conjunto de formas de ser e estar no mundo; sempre que perguntados sobre o que o caracteriza, os Guarani afirmam que é o conjunto da reza/fala/comunicação com Nhanderu e com os familiares, da vivência próxima dos parentes, da dança, do hábito de fumar o cachimbo, dos regimes alimentares que evitam comidas com gordura, sal e carnes mal cozidas, entre várias outras práticas socioculturais. Uma pessoa adulta que não vive de acordo com o nhanderekó desagrada a sua alma, que vai aos poucos se afastando dela; seu distanciamento é uma condição para desencadear inúmeras doenças (axy) e a morte. 


\section{As doenças entre os Guarani}

O termo usado na língua guarani para designar doença é axy. Elizabeth Pissolato (2006) observou, no entnato, que o uso da palavra "doença" também é muito comum entre eles, não apenas quando estão dialogando com brancos, mas também em seu dia a dia. Os significados que essa expressão traz aos Nhandeva não são os mesmos que os brancos frequentemente conferem a ela. Entendê-la nesse contexto exige um processo de "desconstrução crítica" na perspectiva de Viveiros de Castro (2002).

A doença, assim como a saúde, corresponde a uma variedade de elementos existentes no mundo e a vários estados possíveis que envolvem o corpo e a alma. Um sinônimo capaz de expressá-la em sua amplitude é "mal". Os males que existem no mundo e impedem a alegria do homem são vistos e denominados pelos Guarani como doenças (SILVA, 2007). Assim, a tristeza que se sente quando não se sabe ao certo o motivo, a saudade em relação a alguém que morreu ou de alguém que se encontra longe, o desânimo para trabalhar, rezar, falar, a raiva e o susto são sintomas de dença. Pissolato (2006) aponta, em sua pesquisa de campo para a produção da tese de doutoramento, que sua filha, ainda muito pequena, que a acompanhava no trabalho de campo, sentia demasiada saudade de seu pai; observando isso, um Guarani ofereceu-lhe remédio para "curar" a saudade.

Esses sentimentos são todas formas de doenças, pois, invariavelmente, tornam a vida na terra mais dolorida, mais difícil, menos alegre e, se não forem curadas, levam à morte, pois, ao mesmo tempo em que ocorrem pelo fato da nhe'e do sujeito estar afastada também impedem que sua alma volte para ele. As doenças atingem, portanto, o corpo, causando nele dores, febre, fraqueza, tontura, entre outras formas de manifestação, o que provoca aborrecimento, confusão e o distanciamento da alma.

As origens das doenças são muito diversas e podem estar ligadas a fontes humanas e não humanas. Há males que provêm da inveja das outras pessoas e são concretizados através da feitiçaria; há outros que provêm das anguéry (almas dos mortos que vagam pela terra), de sacis habitantes da floresta, da mata, do trovão, dos bichos e de outros fenômenos. Alguns desses agentes emissores de doenças se utilizam de pequenos objetos que são inseridos no corpo dos Guarani causando-lhes as enfermidades.

Deve-se observar ainda a existência das doenças, muito temidas entre esses indígenas, têm origem nos animais ou nos mortos. Na concepção dos Guarani, os bichos também têm nhe’e, assim como os mortos e outros seres que estão no mundo (VIVEIROS DE CASTRO, 1996). Quando um Nhandeva sai de casa para realizar atividades rotineiras, pode se deparar com algum outro ser em forma de bicho (de grande ou pequeno porte) ou de um morto. Nesses momentos, se a alma do homem não estiver próxima dele, a alma de quem o encontrou perceberá e tentará estabelecer uma relação de troca com ele, de modo geral por meio de mensagens. Esse momento é descrito pelos Guarani como um episódio em que o bicho (ou morto) conversa com o homem. Na medida em que o homem aceita estabelecer esse diálogo, ele está, por conseguinte, aceitando a alma do bicho ou do morto, criando um vínculo de comunicação e reciprocidade com esta alma. Quando se trata de um animal que aborda o homem, este é acometido pela doença chamada -jepotá; do encontro entre um morto e uma pessoa resulta a morte.

O -jepotá é, no saber nativo, uma força capaz de desumanizar a pessoa e transformá-la física e psiquicamente em bicho (vixo), estado em que o indivíduo passa a representar para os indígenas um Anhã, isto é, um diabo, sendo por isso comum que se refiram a ele como alguém que encarna o demônio. Por outro lado, a medicina dos brancos, presente na aldeia através de uma unidade de saúde com atendimento médico diário, entende os sujeitos portadores desse mal como sendo sofredores de transtornos psíquicos, uma categoria que, até o momento, não tem tido expressão no entendimento indígena. (SANTOS, 2012, p. 52).

Qualquer que seja a fonte emissora da doença, esta só se instala no sujeito se o mesmo 
não estiver com sua alma devidamente perto de si. O afastamento da alma da pessoa, e daí o início de males, deve ser entendido como o resultado das próprias ações dos homens (da não consideração dos preceitos divinos), caracterizadas, mormente, pelas infrações ao código moral: "De nuestro imperfecto vivir se apoderan de nosotros nuestras enfermidades", diz um informante de Leon Cadogan (1959, p.107).

A mata, assim como alguns animais domésticos, tem um importante papel na proteção dos homens contra os axy; para se ter uma ideia, os cachorros que os Guarani mantêm em casa são, em geral, muito magros, repletos de parasitas e de doenças que se apresentam na forma de grandes feridas na pele, nos olhos, ou em algum outro membro do corpo. Os informantes da Tekohá Añetete asseguram que quanto mais forte é a doença que acomete aos cães mais agressiva ela é aos homens. A mata, como já observou Adriana C. R. Albernaz (2009), embora também possa enviar doenças, é responsável por reter várias delas; assim como barra os raios solares, impedindo as secas, ela segura algumas enfermidades, especialmente aquelas mandadas por pessoas que vivem em outras aldeias. A diminuição das áreas de floresta, ocasionada pelos "ocidentais", é uma das explicações para a proliferação de doenças contraídas após o contato com os brancos.

Assim, a proximidade dos Guarani com os não indígenas os levou a contrair "doenças de branco" (aquelas que os indígenas só conheceram após o contato com os colonizadores, tai como: gripe, desnutrição, entre outras). Estas enfermidades afetam, também, segundo os Nhandeva, a alma. Para que se possa enteder isso, José Catu, informante da aldeia, exemplificou:

Supor: eu e você estamos aqui juntos. Daí a gente passa o dia inteiro caminhando, andando, fazendo uma coisa aqui, trabalhando assim. Tá, tudo bem. De noite eu já sinto uma dor na garganta, incomoda, já percebe que não tá bom. No outro dia vou ver e estou com aquela que é... inflamação, mas só que você não tá. Então isso é porque a minha alma não tá bem, por isso eu fiquei doente e você não. Daí eu tenho que rezar, pedir pro Deus me ajudar, deixar a minha alma alegre, contente que daí eu não vou mais ficar doente. (JOSÉ CATU, Depoimento em 20 de setembro de 2011).

Rafael Mendes Junior (2009) afirma que entre esses indígenas a doença não é apenas um estado fisiológico, pois ela mantém uma ligação íntima com a alma. É o afastamento da nhée do homem que o leva a contrair alguma doença. Se em um determinado momento ou lugar de contato com os não indígenas o índio estiver com a alma alegre e perto de si e fica imune das doenças (ALBERNAZ, 2009).

$\mathrm{O}$ que para os não indígenas se configura como uma doença em si, para os Guarani nã passa de um sintoma; por exemplo: um branco tenderia a ver a inflamação na garganta ou a catarata que atinge os olhos como doenças; nossos informantes veem isso como sendo um sintoma, uma expressão dessa doença. A doença é muito mais que o sintoma. Ela se expressa através do susto, da tristeza, da raiva, (...); as pessoas normalmente não sabem a doença do outro; quem sabe é o pajé, ocasionalmente um ou outro parente bem próximo e, por vezes, o sujeito portador do mal; os demais costumam apenas saber os sintomas. Um depoente da Tekohá Añetete se referiu ao se pai cego dizendo: "Eu não sei bem o que ele tem. Ele tá com aquela que é... catarata, mas a doença mesmo eu não sei. Faz muito tempo já.... (JOSÉ CATU, Depoimento em 20 de setembro de 2011).

Os remédios (naturais ou industrializados) podem ser eficientes no alívio dos sintomas; a cura da doença só pode ser atingida, porém, com o trabalho do pajé.

\section{"Pra nós estraga muito dar muito remédio": os remédios entre os} Guarani

Dihel e Grassi (2010, p. 1556), ao desenvolverem seus estudos em uma comunidade Guarani de Santa Catarina, colheram depoimento de uma informante que confessou suspender o uso de medicamentos assim que os sintomas a aliviavam: "Eu nunca dou assim até o final porque 
pra nós estraga muito dar muito remédio. A gente dá até que melhora, aí já para”. Essa concepção de que o remédio "estraga" a saúde dos indígenas é corrente também na comunidade Tekohá Añetete. Mas afinal, o que o remédio estraga?

Ao afirmarem que os remédios industrializados estragam o corpo, os Guarani estão buscando dizer que tais medicamentos deixam o corpo "pesado" e ocultam doenças, as quais, se não forem percebidas cedo, levam a uma morte silenciosa.

Segundo os Nhandeva o corpo não é apenas um atributo físico, ou seja, uma estrutura fisiológica dada pela natureza. Para eles o corpo é uma produção; é o resultado de uma série de práticas e hábitos. É comum ouvir nas aldeias que ações como dançar, participar dos rituais na casa de rezas, fumar o cachimbo e praticar o nhanderekó fazem o corpo ficar leve. Ao afirmarem isso, os Guarani não estão se referindo ao corpo físico e sua massa, mas ao corpo como uma "roupa" que os indivíduos vão agregando e modificando ao longo da vida por meio de um processo constante de fabricação que se realiza através dos costumes diários (VIVEIROS DE CASTRO, 1996). Fazer com que o corpo seja leve é um ideal de vida para esses sujeitos.

O consumo de remédios industrializados é uma prática que conspira contra esse ideal; ele faz o corpo ficar "pesado", pois não está inscrito no nhanderekó. Um sujeito que consome uma vez um remédio farmacológico terá vontade de fazer isso outras vezes; sempre que tiver alguma dor vai preferir esse medicamento e, com isso, vai abandonar os chás e as ervas naturais colocadas na terra pelo Deus Nhanderu para que os homens pudessem viver bem.

A resistência que os Guarani fazem ao remédio industrializado não é, portanto, pelas suas propriedades químicas; não são elas que estragam o corpo; o que o estraga é o abandono dos hábitos considerados bons. A opção pela farmácia do "Juruá" (branco) significa para o Nhandeva a renúncia ao ensinamento indígena. Tomar remédio de branco deixa o corpo pesado porque esta não é uma prática do bom jeito de viver.

Além disso, segundo os Guarani, os remédios também estragam a pessoa porque eles servem apenas para aliviar os sintomas de uma doença: a inflamação, as dores, os desconfortos. A doença em si, sempre produto de um afastamento da alma, só pode ser curada pelo trabalho do pajé que, com a ajuda dos seus auxiliares, tenta tirar o mal do sujeito e traze-lo para perto da sua alma, reestabelecendo a saúde (ALBERNAZ, 2009, p. 190).

Aquele que não procura o rezador e opta por tomar diretamente o remédio industrializado está correndo sério risco, pois não sabe ao certo qual doença que o acomete. Se estiver se tratando de um mal bastante agressivo, o medicamento apenas ocultará os sintomas, ao passo que a alma adoecida irá cada vez mais se distanciando, até ir embora de vez, ocasionando a morte.

Quando o rezador anuncia a cura da pessoa enferma ela passa a estar dispensada de prosseguir o tratamento com medicamentos. Não tem por que continuar administrando o remédio se a sua alma já voltou para o sujeito. Persistir na medicação só vai contribuir para deixar o corpo pesado e "estragá-lo".

Os remédios naturais também podem inibir os sintomas das doenças, por isso os Guarani recomendam que o sujeito, ao sentir uma dor, recorra primeiro ao karaí; este irá ver o que, de fato, está acometendo a alma da pessoa. Os tratamentos com remédios naturais são, no entanto, bem-vistos pelos Guarani pois fazem parte do nhanderekó. Ao se anunciar a cura de um indivíduo, os chás podem continuar sendo tomados ainda por alguns dias. É uma forma de a alma, que acabou de regressar, sintirse cuidada e motivada a permanecer junto do sujeito.

Apesar dos remédios naturais integrarem as boas práticas do modo de viver Guarani, tal como os informantes de Dihel e Grassi (2010), os Nhandeva do Oeste do Paraná afirmam que hoje não é mais possível viver sem a "farmácia dos brancos". Duas razões são apontadas para isso:

- Primeiro - a destruição das matas levou ao desaparecimento de muitas ervas usadas na terapêutica indígena. Atualmente é comum que o rezador indique para um sujeito enfermo o consumo de chá feito a partir de plantas completamente escassas na região, sendo necessário o envio de 
alguém para aldeias situadas no Paraguai, onde o vegetal ainda pode ser encontrado. Vários tratamentos já não podem ser mais receitados pelo rezador, em função da falta de matéria-prima na natureza. A tradição primitiva que, apesar das migrações e das sucessivas gerações, naturalizava certas plantas sagradas “(...) cujo protótipo eterno cresce na morada dos deuses" (CADOGAN, 1967, p, 300).

- Segundo: o consumo, por indígenas, de alimentos industrializados (condição para sobrevivência em tempo de terras tão escassas) provoca e agrava os sintomas das doenças. A utilização dos remédios industrializados, de origem similar a dos produtos alimentícios, estão agravando os desajustes na saúde dos Guarani. Os informantes dizem que produtos comprados em supermercado tais como: óleo de soja, suco em pó, biscoitos, refrigerantes, fermento químico, entre outros, provocam dores no estômago, febre e fraqueza. As substâncias presentes nesses alimentos desencadeiam ou potencializam sofrimentos que as ervas demoram muito para curar, pois estas são de origem natural enquanto a dor provém daquilo que a indústria produz.

Há, portanto, visível necessidade de os indígenas terem acesso a esses medicamentos. Dihel (2001) informa, acerca de uma aldeia Kaingang no Estado de Santa Catarina, que os sujeitos, mesmo não tendo nenhum sintoma, consultavam com o médico no intuito apenas de "conseguir remédio". Essa prática também acontece entre os Guarani da aldeia Tekohá Añetete; é necessário, porém, compreender o sentido que o medicamento assume neste contexto. Segundo os Nhandeva, quando vão deliberadamente à procura de remédio no posto de saúde, já sabem qual doença têm, pois o rezador a revelou. Sabendo qual é a patologia, sabem também quais sintomas poderão surgir (febre, inflamação, entre outras manifestações); neste caso, assim que se descobrem portadores de uma enfermidade procuram ter um pequeno estoque de remédios, a serem utilizados em casos que os sintomas se manifestem.
Os Guarani se veem, portanto, em uma difícil situação: de um lado o medo de estragar o corpo com uso dos medicamentos, e, de outro, a necessidade do seu uso, em virtude dos recursos naturais cada vez mais escassos, para aliviar dores e desconfortos provocados ou agravados pelo consumo de alimentos industrializados, sem os quais já não podem viver. Essa situação faz com que os Guarani criem formas muito particulares de se relacionar com o fenômeno saúde-doença. Há que se aprofundar os estudos dessas questões.

\section{Considerações finais}

Os Guarani Nhandeva possuem um modo muito particular de perceber saúde e doença. É preciso compreender a concepção nativa. Olhar para ela e pensá-la a partir dos sentidos das sociedades envolventes é incorrer em grandes equívocos.

Dihel e Grassi (2010) nos mostraram que os Guarani, como os demais povos indígenas do Brasil, são consumidores de remédios provenientes da indústria. Um olhar desatento para essa prática poderá levar o observador a pensar: "o rezador perdeu seu lugar na sociedade tradicional" ou "a medicina dos brancos é suficiente para promover a saúde desses povos". Nada mais ilusório do que essas presunções. Tal etnocentrismo precisa ser superado.

A Política Nacional de Atenção à Saúde Indígena implantou dentro das aldeias os serviços da medicina dos "brancos", mas estes foram ressignificados pelos Guarani. Toda vez que esses sujeitos vão ao Posto de Saúde da sua comunidade consultar ou buscar remédios, o fazem movidos pelos sentidos próprios da sua cultura. Nesses momentos, conforme mostramos, o afã de aliviar os sintomas é maior do que o de curar uma doença. Nenhum Guarani iria a um posto de saúde para buscar a cura. Eles sabem que é inútil.

O medicamento, o médico, o enfermeiro, a enfermaria e o assistente social têm grande importância na promoção da saúde dessa sociedade, mas, em última instância é ela que dimensiona o sentido da saúde-doença a partir da sua vivência e da sua cosmovisão. 
Roque de Barros Laraia (1997), ao descrever a morte por fantasma entre os Kaapor, já nos ensinou que o modo como cada sociedade enxerga o mundo determina o que os sujeitos sentem em seu corpo e, até, do que eles morrem. Naquele contexto, um único comprimido de vitaminas era suficiente para salvar a pessoa de uma morte terrível; entre os Guarani nem mesmo o mais potente dos medicamentos industrializados pode curar uma "simples" doença.

Esse fato reitera a importância dos profissionais da medicina dos brancos persistirem naquilo que Langdon, já chamou de relativização da biomedicina:

(...) relativizar a biomedicina significa que seus profissionais precisam reconhecer as suas limitações e admitir que existem outros sistemas médicos que podem contribuir para o conhecimento e a implementação de projetos e programas em saúde. Essa é a premissa fundamental para o respeito às especificidades de cada povo indígena (LANGDON, 2000 apud DIEHL, 2001, p.163).

\section{Referências}

ALBERNAZ, Adriana Cristina Repelevicz. Antropologia, histórias e temporalidades entre os Ava-Guarani de Oco'y (PR). Tese (Doutorado em Antropologia Social) - Programa de Pós-Graduação em Antropologia Social da UFSC, Florianópolis, 2009, 427 p.

BERTONI, Moisés Santiago. La civilización Guaraní. Parte III: Etnografía: conocimientos. La higiene guaraní y su importancia científica y práctica. La medicina guaraní: Conocimientos científicos. Puerto Bertoni: Ex Sylvis, 1927.

CADOGAN, León. En torno a dos plantas y un animal sagrado de los Guaranies. Suplemento Antropológico, Asunción, v. 2, n. 2, p. 299-314, 1967.

CADOGAN, León. Nociones de medicina MbyáGuaraní, Revista Guarania, n. 6, p. 47-61, sept./oct. 1948.
DIEHL, Eliana Elisabeth. Entendimentos, práticas e contextos sociopolíticos do uso de medicamentos entre os kaingáng (terra indígena Xapecó, Santa Catarina, Brasil). Tese (Doutorado) - Escola Nacional de Saúde Pública, Rio de Janeiro, 2001, 230 p.

DIEHL, Eliana Elisabeth; GRASSI, F. Uso de medicamentos em uma aldeia Guarani do litoral de Santa Catarina, Brasil. Cadernos de Saúde Pública, v. 26, n. 8 , p. 1549-1560, 2010.

FABREGA, Horacio. Medical Anthropology. Biennial Review of Anthopology, Stanford University Press, v. 7, p. 167-229, 1971.

LARAIA, Roque de Barros. Cultura: um conceito antropológico. Rio de Janeiro: Jorge Zahar, 1997.

MELLO, Flávia Cristina. Mbyá eChiripá:identidades étnicas, etnônimos e autodenominações entre os Guarani do sul do Brasil. Tellus, Campo Grande, n. 12, ano 7, p. 49-65, 2007.

MENDES JUNIOR, Rafael Fernandes. Os animais são muito mais que algo somente bom para comer. Dissertação (Mestrado em Antropologia) Programa de Pós-Graduação em Antropologia da UFF, Niterói, 2009, 130 p.

MONTENEGRO, Pedro, SJ. Materia médica misionera. Posadas: Editorial Universitária/ UNAM, 2007.

NIMUENDAJU, Curt Unkel. As Lendas da criação e da destruição do mundo como fundamentos da religião dos Apapocúva-Guarani. São Paulo: EDUSP. 1987.

PISSOLATO, Elizabeth de Paula. A duração da pessoa: mobilidade, parentesco e xamanismo mbya guarani. Tese (Doutorado em Antropologia Social) - Museu Nacional, Rio de Janeiro, 2006, 446 p.

SANTOS, Jovane Gonçalves dos. Entre homens e diabos: uma etnografia dos Guarani Nhandáva acometidos pelo -jepotá. Dissertação (Mestrado em Ciências Sociais) - PPCS UNIOESTE, Toledo, 2012, $152 \mathrm{p}$. 
SCHADEN, Egon. Aspectos fundamentais da cultura Guarani. São Paulo: Difusão Europeia do Livro, 1962.

SILVA, Evaldo Mendes. Folhas ao vento: a micromobilidade de grupos Mbyá e Nhandeva (Guarani) na Tríplice Fronteira. Rio de Janeiro: Tese (Doutorado em Antropologia Social) - Museu Nacional, Rio de Janeiro, 2007, 217 p.
VIVEIROS DE CASTRO, Eduardo. O nativo relativo. Mana, Rio de Janeiro, v. 8, n. 1, p. 113-148, 2002.

- Os pronomes cosmológicos e o perspectivismo ameríndio. Mana, Rio de Janeiro, v. 2, n. 2, p. 115-144, 1996. 